\title{
OPEN Controlled diabetes amends oxidative stress as mechanism related to severity of diabetic retinopathy
}

\author{
Rania Fahmy ${ }^{1,2}$, Nouf M. Almutairi ${ }^{3}$, May N. Al-Muammar ${ }^{4}$, Ramesa Shafi Bhat ${ }^{5 \bowtie}$, \\ Nadine Moubayed ${ }^{6}$ \& Afaf El-Ansary 7,8
}

Oxidative stress is a well-accepted etiological mechanism that contributes to neuronal dysfunction. Role of oxidative stress as a mechanism of retinopathy in controlled type 2 diabetic patients was evaluated. Participants were divided into three groups: Group 1 as 30 normal eyes of 15 subjects, Group 2 comprised 24 eyes of 12 diabetic patients without retinopathy and Group 3 comprised 23 eyes of 12 diabetic patients with different grades of retinopathy ( 8 eyes with maculopathy). A complete ophthalmological examination was performed. Oxidative stress markers were measured in blood. Macular thickness was different in all quadrants among all groups and showed a tendency to increase in Group 3 due to diabetic retinopathy with insignificant changes in parapapillary retinal nerve fiber layer thickness although thinning was noted also with retinopathy. Non-significant differences in GST and lipid peroxide levels were observed between the three studied groups, whereas vitamin C and GSH levels were higher in diabetic patients when compared to those in controls. As oxidative stress, hyperglycemia and local inflammation are involved in the pathogenesis of $D R$, the present study proved that the progressive damage can be retarded in controlled type 2 diabetic patients using different treatment modalities that abated oxidative stress.

Diabetes mellitus is a group of metabolic diseases characterized by hyperglycemia due to defects in insulin production and/or insulin action together with impaired carbohydrates, lipids, and protein metabolism. It has long term health complications due to the damage, dysfunction, and failure of different organs ${ }^{1}$. In addition to the kidneys, blood vessels, nerves, and heart, the eyes are greatly affected leading to diabetic retinopathy. However, diabetic patients vary in their predisposition to the development of these complications ${ }^{2}$. The appearance, timing, and severity of each complication in a given patient are largely determined by these factors. Retinopathy is considered to be a predictive status of cardiovascular disease (CVD), and demonstrates fivefold higher risk of developing CV complications ${ }^{3}$. The genetic hypothesis suggests that complications from diabetes are genetically controlled; the metabolic hypothesis suggests that complications such as cellular and vascular damage are mostly relative to the level and duration of hyperglycemia ${ }^{4}$. Ethnicity influences the rate of development of diabetesrelated complications. Complications can be delayed and reduced by maintaining tight glycemic control, avoiding oxidative stress, and local inflammation ${ }^{2}$.

It is still not clear why these complications develop in some patients with poor glycemic control and not in others. Previous studies suggested that hyperglycemia-induced cellular damage, oxidative stress and reactive oxygen species (ROS) are key players for mediating the development of diabetic complications, including retinopathy ${ }^{5}$. Several factors including, ethnicity, genetic susceptibility to damage, environmental factors and co-morbidities are contributors to the predisposition to DM complications. ROS cause strand breaks in nuclear

${ }^{1}$ Department of Optometry, College of Applied Medical Sciences, King Saud University, Riyadh, Saudi Arabia. ${ }^{2}$ Department of Ophthalmology, Faculty of Medicine, Cairo University, Giza, Egypt. ${ }^{3}$ Department of Optometry, King Saud Medical City, Riyadh, Saudi Arabia. ${ }^{4}$ Clinical Nutrition Department, College of Applied Medical Sciences, King Saud University, Riyadh, Saudi Arabia. ${ }^{5}$ Biochemistry Department, College of Science, King Saud University, Riyadh, Saudi Arabia. ${ }^{6}$ Botany Department, College of Science, King Saud University, Riyadh, Saudi Arabia. ${ }^{7}$ Central Laboratory, Female Center for Medical Studies and Scientific Section, King Saud University, Riyadh, Saudi Arabia. ${ }^{8}$ Therapeutic Chemistry Department, National Research Centre, Dokki, Cairo, Egypt. ${ }^{\otimes}$ email: rbhat@ksu.edu.sa 


\begin{tabular}{|l|l|l|l|}
\hline Variables & Group 1 $($ mean \pm SD) & Group 2 $($ mean \pm SD) & Group 3 $($ mean \pm SD) \\
\hline Age (years) & $47.2 \pm 4.69(40-58)$ & $46.83 \pm 6.14(40-56)$ & $52.41 \pm 6.34(40-60)$ \\
\hline Duration of DM (years) & & $7.5 \pm 8.14$ & $12.58 \pm 8.08$ \\
\hline IOP (mmHg) & $17.86 \pm 3.62$ & $18.5 \pm 2.85$ & $20.20 \pm 2.65$ \\
\hline Visual acuity (log Mar) & $0.08 \pm 0.21$ & $0.06 \pm 0.12$ & $0.24 \pm 0.34$ \\
\hline Refractive error (diopters) & $-1.08 \pm 2.84$ & $-0.61 \pm 1.31$ & $-4.97 \pm 15.48$ \\
\hline
\end{tabular}

Table 1. Demographic features of control and controlled diabetic patients with and without retinopathy.

DNA and activate downstream pathways that lead to pancreatic $\beta$ cell damage. This mechanism influences microvascular and macrovascular complications ${ }^{6,7}$.

Previous studies have demonstrated that in T2DM, hyperglycemia-induced polyol pathway flux stimulates ROS interaction within the cell ${ }^{8,9}$. The changes in the polyol pathway flux include increased aldose reductase enzyme activity thus resulting in excessive sorbitol and NADP $+{ }^{10}$. The changed metabolic environment usually leads to a decrease in cellular NADPH thereby leading to a reduction in NADPH dependent synthesis of the protective antioxidant glutathione $(\mathrm{GSH})^{11,12}$.

Based on the fact that several oxidative stress biomarkers have been identified to play a critical role in the pathogenesis of T2DM, and that many of these markers affect retinopathy as a curve status of CVD, the objective of this study is to find the contribution of GSH, vitamin C, GST together with lipid peroxides as markers of antioxidant/oxidative stress signaling in the development of retinopathy in medically controlled T2DM.

\section{Results}

A total of 77 eligible eyes of 39 participants were enrolled into the study. One eye in Group 3 was not analyzed because of media opacity. Table 1 lists the demographic data from 15 control participants (Group 1) and 24 diabetic participants 12 without and 12 with retinopathy (Group 2 and 3, respectively). Age, intraocular pressure, and refractive error that affect the RNFLT were not statistically different among the groups.

The inner and outer macular thicknesses in four quadrants around the macula in both eyes (OD \&OS) were measured by 3D- OCT 2000 is shown in Tables 2 and 3. The macular thickness was different in all quadrants among all groups and tends to increase in Group 3 due to DR except in inner superior quadrants of both eyes. However, a comparison of the macular thickness in the four quadrants among all groups (b P) revealed no statistical difference except in the inner and outer inferior and outer temporal quadrants of the right eye $(\mathrm{P}=0.085,0.083$ and 0.031 respectively) and the inner inferior quadrant of left eye $(\mathrm{P}=0.044)$. Only the inner inferior macular thickness of the left eye was significantly different in Group 2 compared to Group 1 (a $\mathrm{P}=0.049)$.

Table 4 demonstrates the RNFLT around the optic disc measured in both eyes (OD\&OS) for all groups. Comparing the control group with diabetic groups, no significant differences were found although thinning was noted with retinopathy.

Table 5 demonstrate the levels and the percentage changes of GSH, GST, lipid peroxides and vitamin C in controlled diabetic patients with and without retinopathy compared to healthy controls. GST and lipid peroxides did not show any significant difference between the three studied groups; vitamin C and GSH were unexpectedly higher in controlled diabetic patients compared to control participants.

Table 6 and Fig. 1 demonstrate the positive correlations between vitamin C and GST and macular thickness based on biochemical and ophthalmological measures respectively.

Table 7 and 8 represent the stepwise multiple regression analysis using GST, vitamin C, and GSH as dependent variables. Figure 2a,b demonstrate the ROC analysis of the measured biochemical markers in diabetic with and without retinopathy. Among the four parameters, vitamin C and GSH demonstrate predictive values. Table 9 represents the remarkable increase of the area under the curve (AUC) of combined vitamin C and GSH.

\section{Discussion}

This study proved the effectiveness of metabolic control through medications in ameliorating the effect of oxidative stress as pathophysiological mechanism in many diseases among which is DM. Unexpectedly, higher GSH and vitamin $\mathrm{C}$ as anti-oxidants concomitant with non-significantly lower lipid peroxides as marker of oxidative stress were observed in controlled diabetic patients with or without retinopathy compared to healthy non diabetic control.

Ophthalmological results revealed different macular thickness in all quadrants among the three groups with relative increase in group 3 due to DR (Tables 2 and 3 ).

Retinal nerve fiber layer loss associated with diabetic retinopathy develops before clinically detectable retinal vascular pathology and increases in severity with disease progression ${ }^{18}$ and this is the reason of the usefulness of OCT for the early detection of $\mathrm{DR}^{19}$.

The macular thickness differed among groups and increased with disease severity. Previous studies have also reported that macular thickness increased gradually with the progression of DM due to increased retinal vascular permeability and ischemia ${ }^{20}$.

The measured peripapillary RNFLT using 3D-2000 Spectral Domain OCT revealed a similar trend to that of previous studies ${ }^{21}$. The NFL thickness was decreased in clinically detectable DR and the thinning increased with disease severity. 


\begin{tabular}{|c|c|c|c|c|c|c|c|c|c|}
\hline \multicolumn{2}{|c|}{ Parameter } & \multirow{2}{*}{$\begin{array}{l}\text { Group } \\
\text { Group I }\end{array}$} & \multirow{2}{*}{\begin{tabular}{|l|}
$\mathbf{N}$ \\
15
\end{tabular}} & \multirow{2}{*}{\begin{tabular}{|l|} 
Min \\
231.00 \\
\end{tabular}} & \multirow{2}{*}{\begin{tabular}{|l|} 
Max \\
294.00
\end{tabular}} & \multirow{2}{*}{$\begin{array}{l}\text { Mean } \pm \text { SD } \\
264.67 \pm 14.39\end{array}$} & \multirow{2}{*}{\begin{tabular}{|l|} 
\% Change \\
100.00
\end{tabular}} & \multirow[t]{2}{*}{ Pvalue $^{a}$} & \multirow{4}{*}{$\begin{array}{l}\text { P value }^{\text {b }} \\
0.085\end{array}$} \\
\hline \multirow{6}{*}{ I } & \multirow{3}{*}{ Out } & & & & & & & & \\
\hline & & \begin{tabular}{|l|} 
Group II \\
\end{tabular} & 12 & 222.00 & 297.00 & $262.25 \pm 22.99$ & 99.09 & 0.976 & \\
\hline & & Group III & 11 & 244.00 & 445.00 & $291.27 \pm 55.73$ & 110.05 & 0.100 & \\
\hline & \multirow{3}{*}{ In } & Group I & 15 & 286.00 & 322.00 & $299.80 \pm 9.76$ & 100.00 & & \multirow{3}{*}{0.083} \\
\hline & & Group II & 12 & 233.00 & 332.00 & $278.42 \pm 27.94$ & 92.87 & 0.221 & \\
\hline & & Group III & 11 & 261.00 & 469.00 & $311.73 \pm 57.87$ & 103.98 & 0.614 & \\
\hline \multirow{6}{*}{ S } & \multirow{3}{*}{ Out } & Group I & 15 & 235.00 & 284.00 & $268.00 \pm 12.96$ & 100.00 & & \multirow{3}{*}{0.274} \\
\hline & & Group II & 12 & 232.00 & 296.00 & $258.42 \pm 17.48$ & 96.42 & 0.316 & \\
\hline & & Group III & 11 & 236.00 & 308.00 & $269.82 \pm 24.54$ & 100.68 & 0.957 & \\
\hline & \multirow{3}{*}{ In } & Group I & 15 & 257.00 & 321.00 & $302.80 \pm 14.96$ & 100.00 & & \multirow{3}{*}{0.209} \\
\hline & & Group II & 12 & 250.00 & 342.00 & $287.92 \pm 23.99$ & 95.08 & 0.219 & \\
\hline & & Group III & 11 & 230.00 & 332.00 & $288.36 \pm 33.83$ & 95.23 & 0.253 & \\
\hline \multirow{6}{*}{$\mathrm{N}$} & \multirow{3}{*}{ Out } & Group I & 15 & 252.00 & 301.00 & $280.27 \pm 13.83$ & 100.00 & & \multirow{3}{*}{0.157} \\
\hline & & Group II & 12 & 200.00 & 308.00 & $268.92 \pm 27.28$ & 95.95 & 0.264 & \\
\hline & & Group III & 11 & 261.00 & 323.00 & $284.73 \pm 17.85$ & 101.59 & 0.805 & \\
\hline & \multirow{3}{*}{ In } & Group I & 15 & 291.00 & 319.00 & $305.93 \pm 9.60$ & 100.00 & & \multirow{3}{*}{0.241} \\
\hline & & \begin{tabular}{|l|} 
Group II \\
\end{tabular} & 12 & 248.00 & 340.00 & $292.75 \pm 23.98$ & 95.69 & 0.183 & \\
\hline & & Group III & 11 & 264.00 & 345.00 & $297.18 \pm 26.16$ & 97.14 & 0.464 & \\
\hline \multirow{6}{*}{$\mathrm{T}$} & \multirow{3}{*}{ Out } & Control & 15 & 242.00 & 272.00 & $260.87 \pm 9.13$ & 100.00 & & \multirow{3}{*}{0.031} \\
\hline & & Group I & 12 & 218.00 & 289.00 & $248.75 \pm 18.18$ & 95.36 & 0.405 & \\
\hline & & \begin{tabular}{|l|} 
Group II \\
\end{tabular} & 11 & 245.00 & 390.00 & $279.27 \pm 44.37$ & 107.06 & 0.158 & \\
\hline & \multirow{3}{*}{ In } & Group I & 15 & 273.00 & 387.00 & $295.60 \pm 27.01$ & 100.00 & & \multirow{3}{*}{0.129} \\
\hline & & \begin{tabular}{|l|} 
Group II \\
\end{tabular} & 12 & 225.00 & 319.00 & $272.08 \pm 26.74$ & 92.04 & 0.211 & \\
\hline & & Group III & 11 & 247.00 & 465.00 & $303.45 \pm 57.19$ & 102.66 & 0.830 & \\
\hline \multirow{3}{*}{\multicolumn{2}{|c|}{ C }} & Group I & 15 & 190.00 & 273.00 & $229.67 \pm 20.32$ & 100.00 & & \multirow{3}{*}{0.395} \\
\hline & & \begin{tabular}{|l|} 
Group II \\
\end{tabular} & 12 & 175.00 & 308.00 & $233.75 \pm 38.49$ & 101.78 & 0.955 & \\
\hline & & Group III & 11 & 149.00 & 364.00 & $251.55 \pm 61.39$ & 109.53 & 0.324 & \\
\hline
\end{tabular}

Table 2. Outer and inner macular thickness $(\mu \mathrm{m})$ in four quadrants of right eye (OD) of controlled diabetic patients with and without retinopathy, compared to healthy control subjects. Comparisons done using oneway ANOVA test between all groups with multiple comparisons (Dunnett test) to compare each group with the control group in all parameters. ${ }^{a} \mathrm{P}$ value between each group and the control group. ${ }^{\mathrm{b}} \mathrm{P}$ value between all groups.

The apoptosis of retinal ganglion cells (RGCs) is intensified in diabetic retinopathy and the death of the RGCs happens early in diabetic eyes ${ }^{22}$. Diabetes-associated NFL loss is caused by ischemia, which is due to retinal microangiopathy ${ }^{23}$. Furthermore, some researchers suggest that neuropathy heralds the vascular changes in early diabetic retinopathy ${ }^{24}$.

Significant changes in lipid metabolism and structure have been reported in diabetic patients suggesting that peroxidative injury may be involved in the development of diabetic complications. Oxidized lipids are able to produce lipid peroxides, also known as malondialdehyde (MDA) as a decomposition product ${ }^{25}$. Our findings of non-significant change in lipid peroxides between diabetic patients with and without DR compared to control (Table 5); are in agreement with the study of Sklodowska et al. ${ }^{26}$ and Pahwa et al. ${ }^{27}$. These studies reported that lipid peroxide concentration was non-significantly different in diabetic patients treated with insulin or oral drug when compared to healthy controls. It is also supported by the recent work of Golizeh et al. ${ }^{28}$, demonstrating nonsignificant change in lipid peroxides, total antioxidant capacity, serum iron, and ferritin in lifestyle modified and diet-controlled diabetes. On the other hand, it is inconsistent with multiple studies which demonstrate significant elevation of lipid peroxides in diabetic patients compared to controls ${ }^{29}$. This discrepancy can be attributed to the fact that patients examined in the current study or in Sklodowska et al.'s ${ }^{26}$ study were under constant medical care and regular check-ups. This can be explained based on the observations of Sato et al. ${ }^{30}$ who recorded $61 \%$ elevation of peroxides in poorly controlled diabetic patients, but unchanged level in controlled diabetic patients. The non-significant increase of lipid peroxides in diabetic patients with retinopathy reported in the present study is not in agreement with the previous study of Aldebasi et. $\mathrm{al}^{31}$ which suggested that in Qassim, Saudi patients with proliferative diabetic retinopathy (PDR) demonstrate lipid alterations and elevated lipid peroxides; they recommended glycemic control and lipid lowering drugs to prevent or at least to postpone loss of vision from retinopathy in type 2 diabetics. However, they concluded that, logistic regression shows that lipid peroxides, LDL, and Apo A1 were not associated with PDR, which support our findings.

Based on the same concept on the effectiveness of diabetes control in ameliorating oxidative stress- related markers, the unexpected remarkable increase of GSH in diabetic patients with and without DR compared to control (Table 5), can find support in the work of Sekhar et al. ${ }^{32}$. This study shows that uncontrolled type 2 DM 


\begin{tabular}{|c|c|c|c|c|c|c|c|c|c|}
\hline \multicolumn{2}{|c|}{ Parameter } & \multirow{2}{*}{$\begin{array}{l}\text { Group } \\
\text { Group I }\end{array}$} & \multirow{2}{*}{\begin{tabular}{|l|}
$\mathbf{N}$ \\
15
\end{tabular}} & \multirow{2}{*}{\begin{tabular}{|l|} 
Min \\
235.00 \\
\end{tabular}} & \multirow{2}{*}{\begin{tabular}{|l|} 
Max \\
328.00 \\
\end{tabular}} & \multirow{2}{*}{$\begin{array}{l}\text { Mean } \pm \text { SD } \\
266.73 \pm 23.70\end{array}$} & \multirow{2}{*}{\begin{tabular}{|l|} 
\%Change \\
100.00 \\
\end{tabular}} & \multirow[t]{2}{*}{ P value $^{\mathrm{a}}$} & \multirow{4}{*}{\begin{tabular}{|l|} 
P value $^{\text {b }}$ \\
0.972
\end{tabular}} \\
\hline \multirow{6}{*}{ I } & \multirow{3}{*}{ Out } & & & & & & & & \\
\hline & & Group II & 12 & 231.00 & 350.00 & $268.25 \pm 33.07$ & 100.57 & 0.986 & \\
\hline & & Group III & 12 & 230.00 & 324.00 & $269.25 \pm 26.06$ & 100.94 & 0.961 & \\
\hline & \multirow{3}{*}{ In } & Group I & 15 & 253.00 & 355.00 & $303.73 \pm 23.24$ & 100.00 & & \multirow{3}{*}{0.044} \\
\hline & & Group II & 12 & 216.00 & 307.00 & $271.17 \pm 27.35$ & 89.28 & 0.049 & \\
\hline & & Group III & 12 & 241.00 & 458.00 & $304.58 \pm 53.64$ & 100.28 & 0.997 & \\
\hline \multirow{6}{*}{ S } & \multirow{3}{*}{ Out } & Group I & 15 & 256.00 & 286.00 & $272.33 \pm 9.08$ & 100.00 & & \multirow{3}{*}{0.241} \\
\hline & & Group II & 12 & 194.00 & 295.00 & $258.08 \pm 26.57$ & 94.77 & 0.253 & \\
\hline & & Group III & 12 & 241.00 & 354.00 & $273.50 \pm 34.65$ & 100.43 & 0.990 & \\
\hline & \multirow{3}{*}{ In } & Group I & 15 & 253.00 & 324.00 & $302.87 \pm 16.51$ & 100.00 & & \multirow{3}{*}{0.413} \\
\hline & & Group II & 12 & 225.00 & 341.00 & $288.08 \pm 30.86$ & 95.12 & 0.332 & \\
\hline & & Group III & 12 & 253.00 & 366.00 & $299.17 \pm 38.14$ & 98.78 & 0.926 & \\
\hline \multirow{6}{*}{$\mathrm{N}$} & \multirow{3}{*}{ Out } & Group I & 15 & 222.00 & 293.00 & $254.60 \pm 15.83$ & 100.00 & & \multirow{3}{*}{0.478} \\
\hline & & Group II & 12 & 201.00 & 279.00 & $244.50 \pm 22.50$ & 96.03 & 0.537 & \\
\hline & & Group III & 12 & 218.00 & 374.00 & $257.17 \pm 39.41$ & 101.01 & 0.958 & \\
\hline & \multirow{3}{*}{ In } & Group I & 15 & 243.00 & 301.00 & $285.13 \pm 16.14$ & 100.00 & & \multirow{3}{*}{0.627} \\
\hline & & \begin{tabular}{|l|} 
Group II \\
\end{tabular} & 12 & 230.00 & 318.00 & $276.00 \pm 23.98$ & 96.80 & \begin{tabular}{|l|}
0.657 \\
\end{tabular} & \\
\hline & & Group III & 12 & 217.00 & 406.00 & $287.00 \pm 45.05$ & 100.65 & 0.982 & \\
\hline \multirow{6}{*}{$\mathrm{T}$} & \multirow{3}{*}{ Out } & Group I & 15 & 259.00 & 311.00 & $284.47 \pm 13.08$ & 100.00 & & \multirow{3}{*}{0.131} \\
\hline & & Group II & 12 & 222.00 & 319.00 & $274.33 \pm 25.02$ & 96.44 & 0.473 & \\
\hline & & Group III & 12 & 260.00 & 374.00 & $295.08 \pm 33.53$ & 103.73 & 0.442 & \\
\hline & \multirow{3}{*}{ In } & Group I & 15 & 285.00 & 323.00 & $302.20 \pm 12.90$ & 100.00 & & \multirow{3}{*}{0.412} \\
\hline & & Group II & 12 & 249.00 & 333.00 & $288.25 \pm 26.48$ & 95.38 & 0.385 & \\
\hline & & Group III & 12 & 254.00 & 409.00 & $302.00 \pm 44.26$ & 99.93 & 1.000 & \\
\hline \multirow{3}{*}{\multicolumn{2}{|c|}{ C }} & Group I & 15 & 186.00 & 364.00 & $236.93 \pm 45.42$ & 100.00 & & \multirow{3}{*}{0.976} \\
\hline & & Group II & 12 & 189.00 & 286.00 & $236.50 \pm 31.13$ & 99.82 & 0.999 & \\
\hline & & Group III & 12 & 191.00 & 336.00 & $239.92 \pm 46.07$ & 101.26 & 0.976 & \\
\hline
\end{tabular}

Table 3. Outer and inner macular thickness $(\mu \mathrm{m})$ in four quadrants of left eye (OS) of controlled diabetic patients with and without retinopathy compared to healthy control subject. Comparisons done using oneway ANOVA test between all groups with multiple comparisons (Dunnett test) to compare each group with the control group in all parameters. ${ }^{\mathrm{a}} \mathrm{P}$ value between each group and the control group. ${ }^{\mathrm{b}} \mathrm{P}$ value between all groups.

patients have severely deficient synthesis of GSH which can be attributed to limited GSH precursor availability. In contrast, control of diabetes can restore GSH synthesis and lower oxidative stress and oxidant damage even in case of persistent hyperglycemia. Recently, Pahwa et al. ${ }^{33}$ reported non-significant change of GSH in diabetic patients compared to healthy control subjects.

Various toxic molecules formed either from external sources or from the normal metabolism must be detoxified in the body. Glutathione S-Transferase (GST) is an important enzyme catalyzing the detoxification of a variety of toxic molecules through the conjugation with reduced Glutathione (GSH) (the first step in a detoxification pathway) $)^{34}$. While many studies reported variable association of GST gene polymorphism and DM, no data related to GST activity is available ${ }^{35}$. The present study shows no significant change in GST activity between DM with and without DR when compared to control (Table 5). This is not in agreement with the recent findings of Pahwa et al. ${ }^{27}$, which showed significant change in the status of GST activity in coronary artery disease (CAD) patients with type $2 \mathrm{DM}$ and insignificant in its activity in CAD without DM type 2 . They suggested that GST activity may be induced to combat the increased oxidative stress in case of CAD with DM type 2 and hence can be speculated to have a protective mechanism.

Many enzymatic and non-enzymatic anti-oxidants are present in the body such as vitamin C, superoxide dismutase and glutathione peroxidase which have the ability to control ROS. However, multiple reports have suggested defective vitamin $\mathrm{C}$ metabolism concurrent with abnormal leukocytes in diabetic patients ${ }^{36}$. The remarkable increase of vitamin $\mathrm{C}$ reported in the present study (Table 5), is further supported by the work of Feillet Coudrey et. $\mathrm{al}^{36}$ which demonstrated an increased antioxidant activity in animals with streptozotocin experimentally-induced diabetes. This is further supported by the work of Kojda and Harrison ${ }^{37}$ which shows that controlled or regularly checked up diabetic patients showed increased antioxidants and reduced diabetic complications. Additionally, the decreased rate of retinopathy seen with the use of a combination of vitamin supplements including vitamin $\mathrm{C}$, can explain the non-significant differences in the macular and Optic nerve thickness in diabetic patients with and without retinopathy, reported in the present study (Table 4$)^{38}$. The significant positive correlations between vitamin C, GST, and macular thickness (Table 6 and Fig. 1), together with the contribution of outer and inner macular thickness as predictor variable in the change of GST, vitamin C, and GSH 


\begin{tabular}{|c|c|c|c|c|c|c|c|c|c|}
\hline & Parameter & Group & $\mathbf{N}$ & Min & Max & Mean \pm SD & \%Change & Pvalue $^{\mathrm{a}}$ & P value $^{\mathrm{b}}$ \\
\hline \multirow{12}{*}{ Right eye (OD) } & \multirow{3}{*}{ I } & Group I & 15 & 231.00 & 294.00 & $264.67 \pm 14.39$ & 100.00 & & \multirow{3}{*}{0.320} \\
\hline & & Group II & 12 & 222.00 & 297.00 & $262.25 \pm 22.99$ & 99.09 & 0.790 & \\
\hline & & Group III & 11 & 244.00 & 445.00 & $291.27 \pm 55.73$ & 110.05 & 0.234 & \\
\hline & \multirow{3}{*}{ S } & Group I & 15 & 286.00 & 322.00 & $299.80 \pm 9.76$ & 100.00 & & \multirow{3}{*}{0.092} \\
\hline & & Group II & 12 & 233.00 & 332.00 & $278.42 \pm 27.94$ & 92.87 & 0.883 & \\
\hline & & Group III & 11 & 261.00 & 469.00 & $311.73 \pm 57.87$ & \begin{tabular}{|l|}
103.98 \\
\end{tabular} & 0.139 & \\
\hline & \multirow{3}{*}{$\mathrm{N}$} & Group I & 15 & 235.00 & 284.00 & $268.00 \pm 12.96$ & 100.00 & & \multirow{3}{*}{0.222} \\
\hline & & Group II & 12 & 232.00 & 296.00 & $258.42 \pm 17.48$ & 96.42 & 0.983 & \\
\hline & & Group III & 11 & 236.00 & 308.00 & $269.82 \pm 24.54$ & 100.68 & 0.239 & \\
\hline & \multirow{3}{*}{$\mathrm{T}$} & Group I & 15 & 257.00 & 321.00 & $302.80 \pm 14.96$ & 100.00 & & \multirow{3}{*}{0.143} \\
\hline & & Group II & 12 & 250.00 & 342.00 & $287.92 \pm 23.99$ & 95.08 & 0.953 & \\
\hline & & Group III & 11 & 230.00 & 332.00 & $288.36 \pm 33.83$ & 95.23 & 0.113 & \\
\hline \multirow{12}{*}{ Left eye (OS) } & \multirow{3}{*}{ I } & Group I & 15 & 104.00 & 170.00 & $134.80 \pm 17.64$ & 100.00 & & \multirow{3}{*}{0.759} \\
\hline & & Group II & 12 & 16.00 & 180.00 & $129.75 \pm 39.16$ & 96.25 & 0.859 & \\
\hline & & Group III & 12 & 64.00 & 170.00 & $126.92 \pm 25.06$ & 94.15 & 0.696 & \\
\hline & \multirow{3}{*}{ S } & Group I & 15 & 95.00 & 193.00 & $133.80 \pm 25.22$ & 100.00 & & \multirow{3}{*}{0.546} \\
\hline & & Group II & 12 & 62.00 & 153.00 & $129.17 \pm 23.56$ & 96.54 & 0.885 & \\
\hline & & Group III & 12 & 40.00 & 171.00 & $121.50 \pm 36.52$ & 90.81 & 0.449 & \\
\hline & \multirow{3}{*}{$\mathrm{N}$} & Group I & 15 & 46.00 & 95.00 & $70.47 \pm 14.63$ & 100.00 & & \multirow{3}{*}{0.552} \\
\hline & & Group II & 12 & 43.00 & 80.00 & $67.50 \pm 10.95$ & 95.79 & 0.841 & \\
\hline & & Group III & 12 & 11.00 & 87.00 & $63.92 \pm 19.53$ & 90.70 & 0.453 & \\
\hline & \multirow{3}{*}{$\mathrm{T}$} & Group I & 15 & 48.00 & 136.00 & $90.20 \pm 26.35$ & 100.00 & & \multirow{3}{*}{0.670} \\
\hline & & Group II & 12 & 59.00 & 125.00 & $89.92 \pm 24.73$ & 99.69 & 0.999 & \\
\hline & & Group III & 12 & 44.00 & 118.00 & $82.33 \pm 22.82$ & 91.28 & 0.636 & \\
\hline
\end{tabular}

Table 4. Optic nerve (RNFLT) $(\mu \mathrm{m})$ in right eye (OD); left eye (OS) of controlled diabetic patients with and without retinopathy compared to healthy control subjects. Comparisons done using one-way ANOVA test between all groups with multiple comparisons (Dunnett test) to compare each group with the control group in all parameters. ${ }^{\mathrm{a}} \mathrm{P}$ value between each group and the control group. ${ }^{\mathrm{b}} \mathrm{P}$ value between all groups.

\begin{tabular}{|c|c|c|c|c|c|c|c|c|}
\hline Parameter & Group & $\mathbf{N}$ & Min & Max & Mean \pm S.D & $\%$ Change & P value ${ }^{\mathrm{a}}$ & P value $^{\mathrm{b}}$ \\
\hline \multirow{3}{*}{ GST $(\mathrm{U} / \mathrm{ml})$} & Group I & 15 & 15.10 & 18.75 & $17.00 \pm 1.05$ & 100.00 & & \multirow{3}{*}{0.200} \\
\hline & Group II & 12 & 13.50 & 18.70 & $16.34 \pm 1.67$ & 96.12 & 0.445 & \\
\hline & Group III & 12 & 10.90 & 18.70 & $15.93 \pm 1.86$ & 93.72 & 0.143 & \\
\hline \multirow{3}{*}{ Lipid Peroxides ( $\mu$ moles MDA/ml) } & Group I & 15 & 0.07 & 0.11 & $0.09 \pm 0.01$ & 100.00 & & \multirow{3}{*}{0.128} \\
\hline & Group II & 12 & 0.07 & 0.09 & $0.08 \pm 0.01$ & 94.86 & 0.266 & \\
\hline & Group III & 12 & 0.08 & 0.10 & $0.08 \pm 0.01$ & 92.96 & 0.099 & \\
\hline \multirow{3}{*}{ Vitamin $C(\mu \mathrm{g} / \mathrm{ml})$} & Group I & 15 & 10.41 & 21.00 & $15.45 \pm 3.40$ & 100.00 & & \multirow{3}{*}{0.001} \\
\hline & Group II & 12 & 18.00 & 41.00 & $26.58 \pm 8.64$ & 172.02 & 0.001 & \\
\hline & Group III & 12 & 13.00 & 35.00 & $24.83 \pm 7.04$ & 160.69 & 0.001 & \\
\hline \multirow{3}{*}{ Glutathione $(\mu \mathrm{g} / \mathrm{dl})$} & Group I & 15 & 63.00 & 93.91 & $75.23 \pm 10.13$ & 100.00 & & \multirow{3}{*}{0.001} \\
\hline & Group II & 12 & 69.00 & 117.00 & $96.51 \pm 13.94$ & 128.29 & 0.001 & \\
\hline & Group III & 12 & 68.11 & 99.00 & $85.62 \pm 10.11$ & 113.80 & 0.046 & \\
\hline
\end{tabular}

Table 5. Mean $\pm S D$ and percentage changes of the four measured parameters in the serum of controlled diabetic patients with and without retinopathy compared to healthy control subjects. Comparisons done using one-way ANOVA test between all groups with multiple comparisons (Dunnett test) to compare each group with the control group in all parameters. ${ }^{a} \mathrm{P}$ value between each group and the control group. ${ }^{\mathrm{b}} \mathrm{P}$ value between all groups.

as dependent variables respectively (Table 7) could support the role of controlled diabetes in amending oxidative stress as etiological mechanism of DR. Tables 8 and 9 and Fig. 2 demonstrate the possibility of using vitamin C, GSH, and macular thickness as biomarkers for the early prediction of DR, These three variables recorded high ROC AUCs and satisfactory specificity and sensitivity.

The obtained data can provide more evidence that conventional routine therapy that lowers glycemic levels can reduce the development and progression of oxidative stress in type 2 diabetic patients ${ }^{39}$. 


\begin{tabular}{|l|l|l|l|}
\hline Parameters & R (Person correlation) & Sig & \\
\hline Vitamin C $(\mu \mathrm{g} / \mathrm{ml})$ with glutathione $(\mu \mathrm{g} / \mathrm{dl})$ & $0.561^{\star *}$ & 0.001 & $\mathrm{P}^{\mathrm{a}}$ \\
\hline Vitamin C $(\mu \mathrm{g} / \mathrm{ml})$ with macular thickness $(\mu \mathrm{m})-\mathrm{C}(\mathrm{OD})$ & $0.365^{*}$ & 0.024 & $\mathrm{P}^{\mathrm{a}}$ \\
\hline GST $(\mathrm{U} / \mathrm{ml})$ with macular thickness $(\mu \mathrm{m})-\mathrm{N}($ out $)(\mathrm{OD})$ & $0.352^{\star}$ & 0.030 & $\mathrm{P}^{\mathrm{a}}$ \\
\hline
\end{tabular}

Table 6. Pearson's correlations between the measured parameters. ${ }^{\star}$ Correlation is significant at the 0.05 level. ${ }^{*}$ Correlation is significant at the 0.01 level. ${ }^{\text {a }}$ Positive correlation.

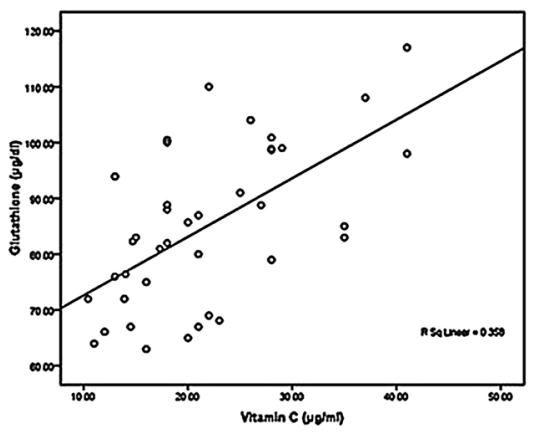

b

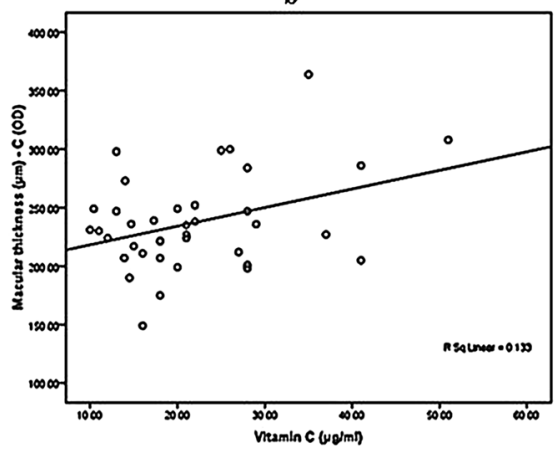

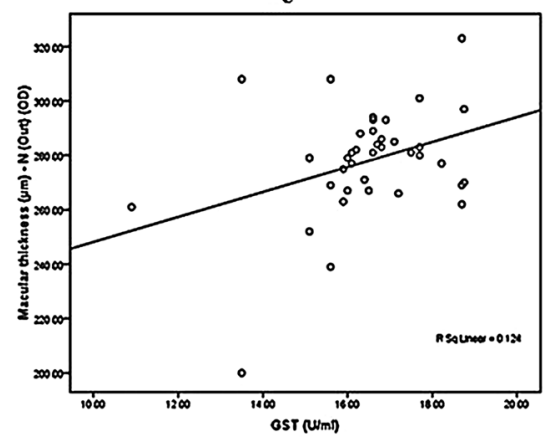

Figure 1. Correlation between (a) vitamin $\mathrm{C}(\mu \mathrm{g} / \mathrm{ml})$ and glutathione $(\mu \mathrm{g} / \mathrm{dl}) ;(\mathbf{b})$ vitamin $\mathrm{C}(\mu \mathrm{g} / \mathrm{ml})$ and macular thickness $(\mu \mathrm{m})-\mathrm{C}(\mathrm{OD}) ;(\mathbf{c}) \mathrm{GST}(\mathrm{U} / \mathrm{ml})$ and macular thickness $(\mu \mathrm{m})-\mathrm{N}(\mathrm{Out})(\mathrm{OD})$ with best fit line curve (positive correlation).

\begin{tabular}{|c|c|c|c|c|c|c|}
\hline \multirow[b]{2}{*}{ Dependent variable } & \multirow[b]{2}{*}{ Predictor variable } & \multirow[b]{2}{*}{ Coefficient } & \multirow[b]{2}{*}{ P value } & \multirow[b]{2}{*}{ Adjusted R square } & \multicolumn{2}{|l|}{ Model } \\
\hline & & & & & F value & P value \\
\hline GST (U/ml) & Macular thickness $(\mu \mathrm{m})-\mathrm{N}(\mathrm{Out})(\mathrm{OD})$ & 0.027 & 0.030 & 0.099 & 5.075 & 0.030 \\
\hline \multirow{3}{*}{ Vitamin C ( $\mu \mathrm{g} / \mathrm{ml})$} & Glutathione ( $\mu \mathrm{g} / \mathrm{dl})$ & 0.358 & 0.001 & 0.362 & 21.956 & 0.001 \\
\hline & Glutathione ( $\mu \mathrm{g} / \mathrm{dl})$ & 0.374 & 0.001 & \multirow{2}{*}{0.431} & \multirow{2}{*}{15.019} & \multirow{2}{*}{0.001} \\
\hline & Macular thickness $(\mu \mathrm{m})-\mathrm{T}(\mathrm{Out})(\mathrm{OD})$ & 0.084 & 0.026 & & & \\
\hline \multirow{3}{*}{ Glutathione $(\mu \mathrm{g} / \mathrm{dl})$} & Vitamin $C(\mu \mathrm{g} / \mathrm{ml})$ & 1.058 & 0.001 & 0.362 & 21.956 & 0.001 \\
\hline & Vitamin $C(\mu \mathrm{g} / \mathrm{ml})$ & 1.121 & 0.001 & 0.432 & 15.083 & 0.001 \\
\hline & Macular thickness $(\mu \mathrm{m})-\mathrm{I}(\mathrm{In})(\mathrm{OD})$ & -0.113 & 0.025 & & & \\
\hline
\end{tabular}

Table 7. Multiple regression using stepwise method for GST (U/ml); vitamin C $(\mu \mathrm{g} / \mathrm{ml})$; glutathione $(\mu \mathrm{g} / \mathrm{dl})$ as a dependent variable.

\begin{tabular}{|c|c|c|c|c|c|c|}
\hline Parameter & Group & Area under the curve & Cut-off value & Sensitivity \% & Specificity \% & P value \\
\hline \multirow{2}{*}{ GST (U/ml) } & Group II & 0.636 & 16.450 & 58.3 & 80.0 & 0.232 \\
\hline & Group III & 0.733 & 16.400 & 66.7 & 80.0 & 0.040 \\
\hline \multirow{2}{*}{ Lipid peroxides ( $\mu$ moles MDA/ml) } & Group II & 0.661 & 0.092 & 91.7 & 53.3 & 0.157 \\
\hline & Group III & 0.700 & 0.090 & 91.7 & 53.3 & 0.079 \\
\hline \multirow{2}{*}{ Vitamin $C(\mu \mathrm{g} / \mathrm{ml})$} & Group II & 0.936 & 17.650 & 100.0 & 73.3 & 0.001 \\
\hline & Group III & 0.872 & 22.000 & 66.7 & 100.0 & 0.001 \\
\hline \multirow{2}{*}{ Glutathione $(\mu \mathrm{g} / \mathrm{dl})$} & Group II & 0.878 & 95.955 & 66.7 & 100.0 & 0.001 \\
\hline & Group III & 0.769 & 73.500 & 91.7 & 53.3 & 0.018 \\
\hline
\end{tabular}

Table 8. ROC-curve of all parameters in all groups. 
$\mathbf{a}$

Roc Curve

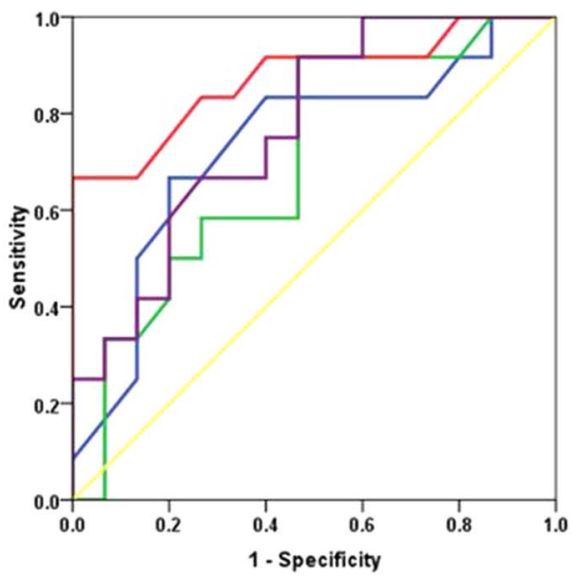

b

ROC Curve

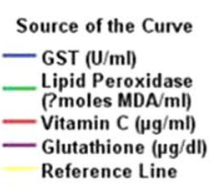

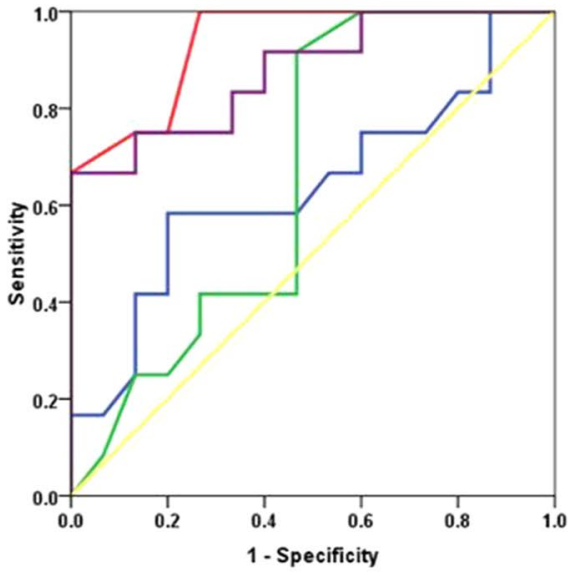

Source of the Curve - GST $(\mathrm{U} / \mathrm{ml})$ - Lipid Peroxidase - Vitamin $C(\mu \mathrm{g} / \mathrm{ml})$ - Glutathione $(\mu \mathrm{g} / \mathrm{dl})$ Reference Line

Figure 2. ROC curve of GST (U/ml), lipid peroxidase ( $\mu$ moles MDA/ml), vitamin $\mathrm{C}(\mu \mathrm{g} / \mathrm{ml})$ and glutathione $(\mu \mathrm{g} / \mathrm{dl})$ in (a) diabetes without retinopathy; (b) diabetes with retinopathy group.

\begin{tabular}{|c|c|c|c|c|c|c|}
\hline Parameter & Group & Area under the curve & Cut-off value & Sensitivity \% & Specificity \% & P value \\
\hline Glutathione $(\mu \mathrm{g} / \mathrm{dl})$ & \multirow[b]{2}{*}{ Group II } & 0.878 & 95.955 & 66.7 & 100.0 & 0.001 \\
\hline $\begin{array}{l}\text { Glutathione ( } \mu \mathrm{g} / \mathrm{dl}) \text { with Macular thick- } \\
\text { ness }(\mu \mathrm{m})-\mathrm{I}(\mathrm{In})(\mathrm{OS})\end{array}$ & & 0.967 & - & 91.7 & 93.3 & 0.001 \\
\hline Vitamin C ( $\mu \mathrm{g} / \mathrm{ml})$ & \multirow[b]{2}{*}{ Group II } & 0.872 & 22.000 & 66.7 & 100.0 & 0.001 \\
\hline $\begin{array}{l}\text { Vitamin C }(\mu \mathrm{g} / \mathrm{ml}) \text { with Macular thick- } \\
\text { ness }(\mu \mathrm{m})-\mathrm{S}(\mathrm{In})(\mathrm{OD})\end{array}$ & & 0.933 & - & 81.8 & 100.0 & 0.001 \\
\hline
\end{tabular}

Table 9. Combined ROC.

\section{Conclusion}

Hyperglycemia is associated with multiple pathophysiological mechanisms that together promote the aggressiveness of DR. Different approaches should be targeted to treat DR. Among these targets, oxidative stress-related medication can be of great help to stabilize the clinical status that may progress to blindness in uncontrolled type 2 diabetic patients.

Clinical implication. Oxidative stress has been implicated in the pathogenesis and progression of DR in both type 1 and type 2-diabetes. Identifying the most effective modalities for preventing retinopathy or intervening at an early, asymptomatic stage is necessary to preserve vision. Thus therapeutic correction of oxidantantioxidant imbalance may be a powerful tool for preventing visual loss associated with DR.

\section{Materials and method}

Subject recruitment. The prospective observational case control study was carried out between October 2016 and April 2017 at medical retina clinic in King Saud Medical City, Riyadh, Saudi Arabia following the STROBE cross sectional reporting guidelines. The subjects of the study were 39 individuals aged between 40 and 60 years, without a previous history of any endocrine, hepatic, metabolic, cardiovascular and renal disease. Chorioretinitis scars, posterior uveitis, ocular hypertension, glaucoma and previous ocular surgery were also excluded. They were divided into three groups: Group 1 comprised 30 normal eyes of 15 subjects, Group 2 comprised 24 eyes of 12 diabetic patients without retinopathy, and Group 3 comprised 23 eyes of 12 diabetic patients with different grades of retinopathy (8 eyes with maculopathy). Diabetic patients were controlled on their medications (oral hypoglycemic and or insulin, multivitamins and lipid lowering drugs) as they are subjected biannually to regular follow up in our hospital measuring hemoglobin A1c that reflect their glycemic control in last 120 days. Each enrolled subject was given a written informed consent. The study was reviewed and approved by the concerned Ethical Committee. All methods were carried out in accordance with relevant guidelines and regulations of the Declaration of Helsinki.

Data collection. All Participants underwent a complete ophthalmological examination including visual acuity assessment by Snellen chart, refraction using autorefractometer, slit-lamp examination, Goldmann applanation tonometry, dilated stereoscopic fundus examination using indirect ophthalmoscope for clinical determination of grade of retinopathy, peripapillary retinal nerve fiber layer thickness (RNFLT) and macular thickness measurements using 3D-2000 Spectral Domain optical coherence tomography OCT that uses 360-degree circu- 
lar scan with $3.4 \mathrm{~mm}$ diameter centered on optic disc to measure RNFLT in four quadrants (inferior, superior, nasal and temporal) and line scan for macula measuring inner and outer macular thickness in four quadrants (inferior, superior, nasal, and temporal).

Blood collection and preparation. Five milliliters of peripheral blood was collected in sterilized plastic vials without anti-coagulate to obtain the serum for biochemical analysis.

Biochemical analysis. Lipid oxidation was estimated by the formation of thiobarbituric acid reactive substances (TBARS) as described previously by Ruiz-Larrea et al. ${ }^{13}$. Vitamin $\mathrm{C}$ was assayed as previously described by Jagota and $\mathrm{Dani}^{14}$. Glutathione was assayed by the method of Beutler et al. ${ }^{15}$ using $5,5^{\prime}$-dithiobis 2-nitrobenzoic acid (DTNB) with sulfhydryl compounds to produce a relatively stable yellow color. Glutathione S-transferase activity (GST) activity was assessed using an assay kit (Biovision, USA) that was based upon the GST-catalyzed reaction between GSH, GST substrate, and CDNB (1-chloro-2,4-dinitrobenzene) ${ }^{16}$.

Statistical analysis. SPSS Version 16.0 program was used for the analysis of the obtained data, and results were expressed as mean \pm S.D. All statistical comparisons were made using one-way ANOVA test between all groups with multiple comparisons (Dunnett test) to compare each group with the control group in all parameters A significant difference was considered at $\mathrm{P}$ value $<0.05$. Multiple Regression using Stepwise method was performed for GST, Vitamin C and Glutathione as a dependent variable. The receiver operating characteristics (ROC) curve was used as a fundamental tool to show which biomarkers were predictive in the development of retinopathy. It was performed using the same SPSS Version 16.0 software. Analyzed data were reported in this study. In a ROC curve, the true positive rate (sensitivity) is plotted as a function of the false positive rate (100-specificity) for different cut-off points of a defined parameter. Each point on the ROC curve represents a sensitivity/specificity pair corresponding to a particular decision threshold. The area under the ROC curve is a measure of how well a parameter can be used as biomarker as AUC of 0.5 suggests no discrimination on the basis of ability to diagnose patients with and without the disease; 0.7 to 0.8 is considered acceptable; 0.8 to 0.9 is considered excellent and more than 0.9 is considered outstanding ${ }^{17}$.

Limitations. Conducting well-designed small studies need careful interpretations. As small studies can provide quick results, it was important to make strong conclusions about oxidative stress as a risk factor for DR, whether the results are positive or not. In addition, data from our studies should be used to design larger confirmatory studies taking into consideration that small studies have their limitations.

Ethical approval. The protocol of the study was explained to each participant at the time of recruitment and written informed consent was obtained. The research was approved by the research ethical committee of King Saud University. All methods were carried out in accordance with relevant guidelines and regulations of the Declaration of Helsinki.

Received: 20 December 2020; Accepted: 2 August 2021

Published online: 03 September 2021

\section{References}

1. Awadallaa, H. et al. Diabetes complications in Sudanese individuals with type 2 diabetes: Overlooked problems in sub-Saharan Africa?. Diabetes Metab. Syndr. 11S, S1047-S1051 (2017).

2. Kou, S. et al. Ethnicity influences cardiovascular outcomes and complications in patients with type 2 diabetes. J. Diabetes Complic. 32(2), 144-149 (2018).

3. Yamada, T. et al. Proliferative diabetic retinopathy is a predictor of coronary artery disease in Japanese patients with type 2 diabetes. Diabetes Res. Clin. Pract. 96(1), e4-e6 (2012).

4. Grunwald, J. E. et al. Retinopathy and the risk of cardiovascular disease in patients with chronic kidney disease (from the Chronic Renal Insufficiency Cohort study). Am. J. Cardiol. 116(10), 1527-1533 (2015).

5. Keen H. Chronic complications of diabetes mellitus. in Chronic Complications of Diabetes Mellitus (Galloway, D.M. ed.). 1-21 (Eli Lilly, 1988).

6. Brownlee, M. Banting lecture 2004: The pathobiology of diabetic complications-A unifying mechanism. Diabetes 54, 1615-1625 (2005).

7. Shah, M. S. \& Brownlee, M. Molecular and cellular mechanisms of cardiovascular disorders in diabetes. Circ. Res. 118, 1808-1829 (2016).

8. Angeline Julius, A. \& Waheeta Hopper, W. A. Non-invasive, multi-target approach to treat diabetic retinopathy. Biomed. Pharmacother. 109, 708-715 (2019).

9. Paneni, F. et al. Diabetes and vascular disease: Pathophysiology, clinical consequences, and medical therapy: Part I. Eur. Heart J. 34(31), 2436-2443 (2013).

10. Sies, H., Berndt, C. \& Jones, D. P. Oxidative stress. Annu. Rev. Biochem. 86, 715-748 (2017).

11. Bhatia, S. et al. Antioxidant status, lipid peroxidation and nitric oxide end products in patients of type 2 diabetes mellitus with nephropathy. Clin. Biochem. 36(7), 557-562 (2003).

12. Liu, C. W. et al. Temporal expression profiling of plasma proteins reveals oxidative stress in early stages of type 1 diabetes progression. Proteomics 172, 100-110 (2018).

13. Ruiz-Larrea, M. B. et al. Antioxidant effects of estradiol and 2-hydroxyestradiol on iron-induced lipid peroxidation of rat liver microsome. Steroids 59(6), 383-388 (1994).

14. Jagota, S. K. \& Dani, H. M. A. New colorimetric technique for the estimation of vitamin C using folin phenol reagent. Anal. Biochem. 15, 178-182 (1982).

15. Henry, J. B. Clinical Diagnosis and Management by Laboratory Method 16th edn. (WB Saunders and Company, 1974).

16. Habig, W. H., Pabst, M. J. \& Jacoby, W. B. Glutathione-S-transferase, the first enzymatic step in mercapturic acid formation. J. Biol. Chem. 249, 7130-7139 (1974). 
17. Yang, L. et al. Grouped variable selection using area under the ROC with imbalanced data. Commun. Stat. Simul. Comput. 45, $1268-1280$ (2001).

18. Oshitari, T., Hanawa, K. \& Adachi-Usami, E. Changes of macular and RNFL thicknesses measured by Stratus OCT in patients with early stage diabetes. Eye (Lond). 23, 884-889 (2009).

19. Lattanzio, R. et al. Macular thickness measured by optical coherence tomography (OCT) in diabetic patients. Eur. J. Ophthalmol. 12, 482-487 (2002).

20. Weinberger, D. et al. Retinal thickness variation in the diabetic patient measured by the retinal thickness analyser. Br. J. Ophthalmol. 82, 1003-1006 (1998).

21. Takahashi, H. et al. Diabetes-associated retinal nerve fiber damage evaluated with scanning laser polarimetry. Am. J. Ophthalmol. 142, 88-94 (2006).

22. Asnaghi, V. et al. A role for the polyol pathway in the early neuroretinal apoptosis and glial changes induced by diabetes in the rat. Diabetes 52, 506-511 (2003).

23. Lim, M. C. et al. Effect of diabetic retinopathy and panretinal photocoagulation on retinal nerve fiber layer and optic nerve appearance. Arch. Ophthalmol. 127, 857-862 (2009).

24. Adams, A. J. \& Bearse, M. A. Jr. Retinal neuropathy precedes vasculopathy in diabetes: a function-basedopportunity for early treatment intervention?. Clin. Exp. Optom. 95(3), 256-265 (2012).

25. Fowler, M. J. Microvascular and macrovascular complications of diabetes. Clin. Diabetes. 26(2), 77-82 (2008).

26. Skłodowska, M., Gromadzińska, J. \& Wasowicz, W. Lipid peroxide concentration, selenium level and glutathione peroxidase activity in blood of type II (non-insulin dependent) diabetic elderly people. J. Clin. Biochem. Nutr. 7(1), 35-41 (1989).

27. Pahwa, S., Sharma, R. \& Singh, B. Role of glutathione S-transferase in coronary artery disease patients with and without type 2 diabetes mellitus. J. Clin. Diagn. Res. 11(1), 05-08 (2017).

28. Golizeh, M. et al. Increased serotransferrin and ceruloplasmin turnover in diet-controlled patients with type 2 diabetes. Free Radic. Biol. Med. 113, 461-469 (2017).

29. Fatani, S. H. et al. Lipid peroxidation is associated with poor control of type-2 diabetes mellitus. Diabetes Metab. Syndr. 10(2 Suppl 1), S64-67 (2016).

30. Sato, Y. et al. Lipid peroxide levels in plasma of diabetic patients. Biochem. Med. 21, 104-107 (1979).

31. Aldebasi, Y. H. et al. Dyslipidemia and lipid peroxidation of Saudi type 2 diabetics with proliferative retinopathy. Saudi Med J. 34(6), 616-622 (2013).

32. Sekhar, R. V. et al. Glutathione synthesis is diminished in patients with uncontrolled diabetes and restored by dietary supplementation with cysteine and glycine. Diabetes Care 34(1), 162-167 (2011).

33. Gontil, N. \& Kadioglu, E. The role of GSTM1, GSTT1, GSTP1 and OGG1 polymorphism in type 2 diabetes mellitus risk: A casecontrol study in a Turkish population. Gene 505, 121-127 (2012).

34. Santl, L. M. et al. Association of manganese superoxide dismutase and gliutathione S-transferase genotypes with carotid atherosclerosis in patients with diabetes mellitus 2. Int. Angiol. 31, 33-41 (2012).

35. Sundaram, R. K. et al. Antioxidant status and lipid peroxidation in type II diabetes mellitus with and without complications. Clin. Sci. (Lond). 90, 255-260 (1996).

36. Feillet-Coudray, C. et al. Lipid peroxidation and antioxidant status in experimental diabetes. Clin. Chim. Acta 284, 31-43 (1999).

37. Kojda, G. \& Harrison, D. Interactions between NO and reactive oxygen species: pathophysiological importance in atherosclerosis, hypertension, diabetes and heart failure. Cardiovasc. Res. 43, 562-571 (1999).

38. Cunningham, J. J. et al. Reduced mononuclear leukocyte ascorbic acid content in adults with insulin dependent diabetes mellitus consuming adequate dietary vitamin C. Metabolism 40(2), 146-149 (1991).

39. Heneka, M. T., Fink, A. \& Doblhammer, G. Effect of pioglitazone medication on the incidence of dementia. Ann. Neurol. 78, 284-294 (2015).

\section{Acknowledgements}

The authors extend their appreciation to the Deanship of Scientific Research at King Saud University, for funding this work through research group number RG-1441-434. The authors thank the Deanship of Scientific Research and RSSU at King Saud University for their technical support".

\section{Author contributions}

R.F.- conceived and designed the experiments; M.N.A.- - analyzed the data; R.S.B.-performed the biochemical experiments and revised the manuscript, N.M.A.- performed clinical examination and collected the samples, N.M. revised the manuscript, A.E.-A.- wrote the manuscript.

\section{Competing interests}

The authors declare no competing interests.

\section{Additional information \\ Correspondence and requests for materials should be addressed to R.S.B.}

Reprints and permissions information is available at www.nature.com/reprints.

Publisher's note Springer Nature remains neutral with regard to jurisdictional claims in published maps and institutional affiliations.

(c) (i) Open Access This article is licensed under a Creative Commons Attribution 4.0 International

License, which permits use, sharing, adaptation, distribution and reproduction in any medium or format, as long as you give appropriate credit to the original author(s) and the source, provide a link to the Creative Commons licence, and indicate if changes were made. The images or other third party material in this article are included in the article's Creative Commons licence, unless indicated otherwise in a credit line to the material. If material is not included in the article's Creative Commons licence and your intended use is not permitted by statutory regulation or exceeds the permitted use, you will need to obtain permission directly from the copyright holder. To view a copy of this licence, visit http://creativecommons.org/licenses/by/4.0/.

(C) The Author(s) 2021 